\title{
Acenocoumarol induced anticoagulant-related nephropathy with newly diagnosed IgA nephropathy: A repeat biopsy case report
}

AGLAIA CHALKIA ( $\sim$ aglaia.chalkia@gmail.com )

General Hospital of Athens Hippokration https://orcid.org/0000-0002-5963-3246

Kourniotis Dimitrios

General Hospital of Athens Hippocration

Aggelis George

General Hospital of Athens Hippocration

Gakiopoulou Harikleia

1st Department of Pathology, National and Kapodistrian University of Athens, Medical School

\section{Petras Dimitrios}

General Hospital of Athens Hippocration

\section{Research Article}

Keywords: Acute Kidney Injury, IgA nephropathy, Anticoagulant-related nephropathy

Posted Date: February 9th, 2022

DOI: https://doi.org/10.21203/rs.3.rs-1034083/v1

License: (9) This work is licensed under a Creative Commons Attribution 4.0 International License. Read Full License

Version of Record: A version of this preprint was published at SN Comprehensive Clinical Medicine on April 2nd, 2022. See the published version at https://doi.org/10.1007/s42399-022-01173-6. 


\section{Abstract}

Anticoagulant-related nephropathy (ARN) is an underestimated cause of acute kidney injury (AKI) with poor renal and overall prognosis. Pathogenesis is not fully elucidated yet, although AKI is probably resulting from glomerular hemorrhage and most commonly has been described in patients with glomerular lesions, that alter the glomerular permeability, and conditions with glomerular hyperfiltration. Herein, we describe a case with a 58-year-old man who presented with macroscopic hematuria and AKI, and recently taking acenocoumarol for aortic valve replacement. The first renal biopsy showed red cell casts in the renal tubules, one glomerular crescent formation in the glomeruli with mild immunoglobulin $\mathrm{A}$ deposition, and severe interstitial inflammation. Based on these findings, the patient was diagnosed with acenocoumarol induced ARN with newly diagnosed IgA nephropathy and switched to tinzaparin with a short course of corticosteroids. Renal improvement in ARN is usually partial and is delayed, as confirmed by a second biopsy in our patient after six months.

\section{Introduction}

Anticoagulant-related nephropathy (ARN) is a type of acute kidney injury (AKI) that may be caused by excessive anticoagulation with warfarin and other anticoagulants [1]. A decade ago, Brodsky et al. described this new clinicopathologic entity as "warfarin-related nephropathy" [2]. The characteristic pathologic findings are the glomerular hemorrhage, the tubular epithelial cell injury, and the obstruction of renal tubules by red blood cell casts, whereas these casts do not contain Tamm-Horsfall protein. However, the glomeruli are not usually involved [2]. The main predisposing features seemed to be excessive anticoagulation (in the first 3 months of warfarin use), older age, diabetes mellitus, obesity, heart failure, and pre-existing kidney disease, including glomerular diseases. In most patients with ARN, the serum creatinine stabilizes or improves slightly within the first few weeks after correction of the warfarin coagulopathy. However, some patients may have little or no recovery of kidney function [2].

\section{Case Presentation}

A 58-year-old Caucasian man presented at the emergency room complaining of 10 days of painful macroscopic hematuria. His medical history included diabetes, hypertension, and obesity. Furthermore, 2 months ago he underwent aortic valve replacement with a mechanical valve and he began taking acenocoumarol (vitamin $\mathrm{K}$ antagonist) as an anticoagulant agent.

The laboratory results at the time of admission are detailed in Table 1. The patient presented with AKI stage 3 (according to the KDIGO classification) and the renal ultrasound showed normal-sized kidneys. 2 months ago, renal function was normal with serum creatinine $0.9 \mathrm{mg} / \mathrm{dL}(0.72-1.25)$. Coagulation test results revealed prothrombin time (PT) and activated thromboplastin time (aPTT) values of 19.2 and 40.1 , respectively, with an international normalized ratio (INR) 3.5. 
Table 1

Laboratory results on admission

\begin{tabular}{|c|c|c|}
\hline Laboratory test & Patient result & Reference range \\
\hline Creatinine, mg/dL & 5.9 & $0.72-1.25$ \\
\hline Urea, mg/dL & 101 & $18-55$ \\
\hline Sodium, $\mathrm{mmol} / \mathrm{L}$ & 140 & $136-145$ \\
\hline Potassium, mmol/L & 3.5 & $3.5-5.1$ \\
\hline Glucose, mg/dL & 170 & $70-105$ \\
\hline Calcium, mg/dL & 8.1 & $8.4-10.2$ \\
\hline Albumin, $\mathrm{g} / \mathrm{dL}$ & 3.6 & $3.5-5$ \\
\hline AST, U/L & 13 & $5-34$ \\
\hline$A L T, U / L$ & 10 & $0-55$ \\
\hline LDH. U/L & 302 & $125-220$ \\
\hline Bilirubin, total, mg/dL & 0.4 & $0.2-1.2$ \\
\hline CRP, mg/L & 50 & $0-5$ \\
\hline WBC count, $x 10 \mathrm{e} 3 / \mathrm{uL}$ & 79.36 & $5.2-12.4$ \\
\hline Platelet count, $x 10 \mathrm{e} 3 / \mathrm{uL}$ & 413 & $130-400$ \\
\hline Hemoglobin, g/dL & 10.1 & $12-18$ \\
\hline \multicolumn{3}{|l|}{ Urine tests } \\
\hline $\mathrm{pH}$ & 6 & $5.5-6.5$ \\
\hline Specific gravity & 1007 & $1015-1028$ \\
\hline RBC/ HPF & $>200$ & $0-2$ \\
\hline WBC/ HPF & $8-10$ & $0-5$ \\
\hline Protein, mg/dL & 150 & $0-20$ \\
\hline
\end{tabular}

The patient denied previous episodes of macroscopic hematuria in the past or kidney family history. He also denied recent episodes of respiratory or gastrointestinal infection. A phase-contrast microscopic examination of the urinary sediment revealed numerous red blood cells, including several dysmorphic erythrocytes and 24-h urinary protein excretion presented $2.5 \mathrm{~g} /$ day. In addition, serologic testing for hepatitis B, hepatitis C, and HIV were negative. Serum complement for C3 192mg/dL (75-180), C4 $55.8 \mathrm{mg} / \mathrm{dL}$ (10-40), IgA 238mg/dL (70-400), IgG 930mg/dL (700-1600), IgM 96 mg/dL (40-230), 
antinuclear antibody, anti-double-stranded DNA and antineutrophil cytoplasmic antibodies were negative. Severe infections including endocarditis, abscess, and respiratory infections were excluded by blood cultures, transesophageal cardiac ultrasound, and PET scan.

After the PT-INR had normalized, a renal biopsy was performed. The biopsy specimen contained 10 glomeruli with mild mesangial hypercellularity and 1/10 (10\%) glomeruli with cellular crescent form. The interstitial renal tissue was filtered with inflammatory cells, mainly lymphocytes, with the presence of acute tubular necrosis and occlusive red blood cell casts. The immunofluorescence revealed mesangial deposits of $\mathbf{I g A}(\mathbf{2 +})$ and $\mathbf{C} 3(\mathbf{1 +})$, and no $\lg \mathrm{M}, \lg G, \mathrm{C} 1 \mathrm{q}, \mathrm{C} 4, \mathrm{k}$, and $\lambda$ light chains.

Based on these histological findings, the patient was diagnosed with acute kidney injury associated with anticoagulant-related nephropathy in the presence of IgA nephropathy. Firstly, he was managed with normal saline infusion, and then pos prednisolone $1 \mathrm{mg} / \mathrm{Kg} /$ daily was added to his treatment, particularly due to the severe interstitial nephritis, with a gradual reduction in 4 months. The patient was discharged home on the 20th day with serum creatinine $3.5 \mathrm{mg} / \mathrm{dL}$ and acenocoumarol was replaced by tinzaparin. After 3 months, although his urine continued to present microscopic hematuria (50-60 red blood cells per high-power field), renal function was improved further and proteinuria was beginning to decrease (Table 2). 
Table 2

Creatinine level and RBC urine changes over time.

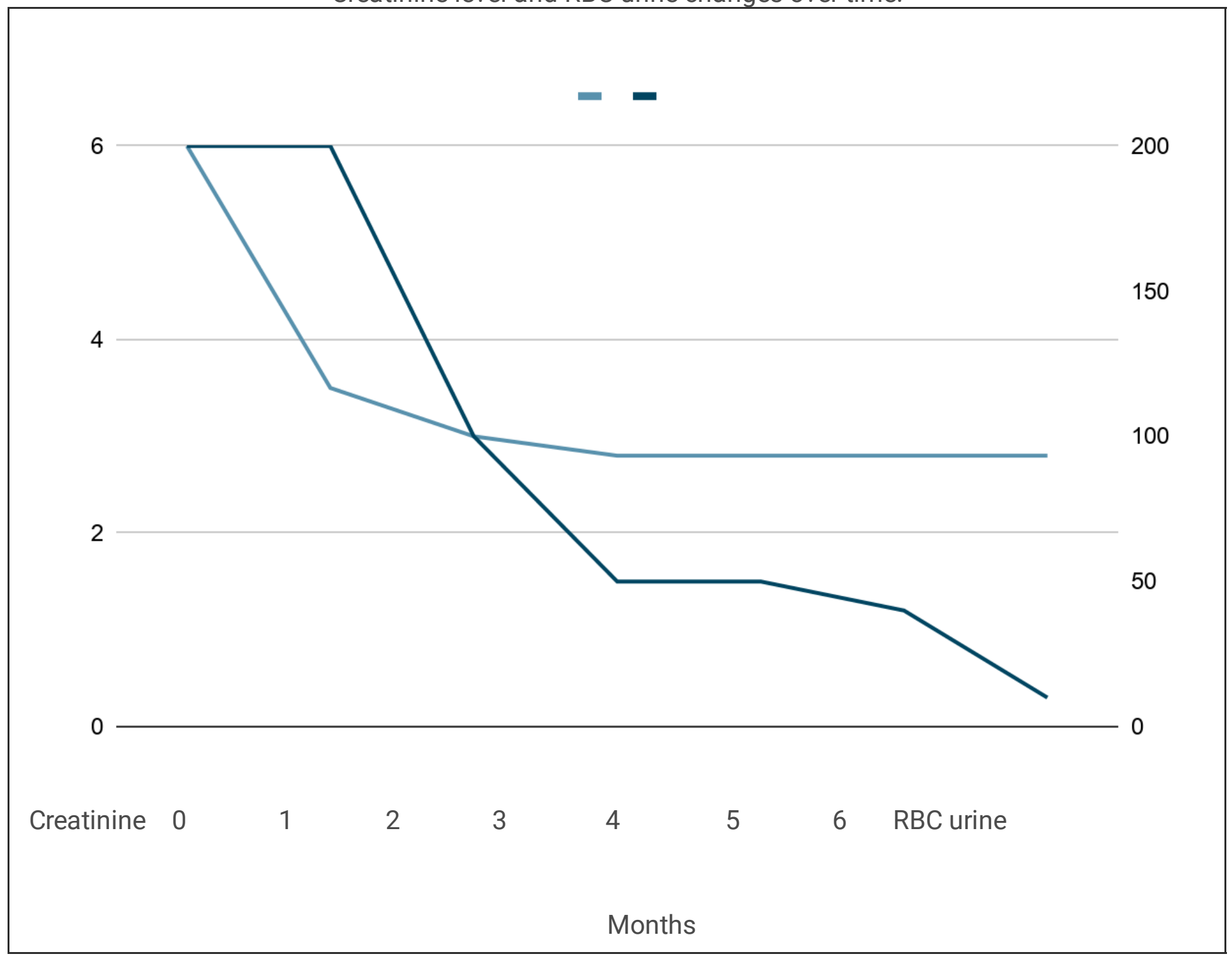

At 6 months the patient presented stable serum creatinine $2.6 \mathrm{mg} / \mathrm{dL}$ and a second kidney biopsy was performed to determine the chronicity/activity index. The biopsy specimen contained 10 glomeruli with mild mesangial hypercellularity and without crescent form. The interstitial fibrosis was extended with minimal inflammation, while the acute tubular injury was yet present without the previous occlusive red blood cell casts. Now, the immunofluorescence was negative.

After 1 year, the patient presents persistent microscopic hematuria but the renal function is further improving (creatinine $2 \mathrm{mg} / \mathrm{dL}$ ).

\section{Discussion}


This case report highlights an unusual cause of AKI "anticoagulant-related nephropathy" [ARN], which is an underdiagnosed entity, for the reason that kidney biopsies have difficulties in patients who receive anticoagulant treatment, because of concerns related to the risk of thrombosis or bleeding. This entity constitutes a severe form of AKI (all cases stage 3 according to KDIGO classification), with the majority of patients requiring hemodialysis on admission. Recently Imperio et al. [3] suggested a clinicopathologic pathway towards the true diagnosis of ARN with the proposed clinical and histological criteria.

It has been reported the description of ARN with the use of all classes of vitamin $\mathrm{K}$ antagonists as well as novel oral anticoagulants. We report here a case of ARN with recent onset of acenocoumarol use (2 months), associated with newly diagnosed IgA nephropathy, because of moderate IgA staining on kidney biopsy, and sub-nephrotic range proteinuria. According to the literature, IgA nephropathy is quite often related to ARN (Table 3), although only 1 case has been described to be induced by acenocoumarol [8], as in our patient. The glomerular permeability alteration is essential for RBC leak to occur during periods of over-anticoagulation and can be related to IgA nephropathy, thin glomerular basement membrane, and nephrosclerosis, resulting in ARN [10]. 
Table 3

Anticoagulant-related nephropathy associated with $\lg A$ nephropathy

\begin{tabular}{|c|c|c|c|c|c|c|c|}
\hline Ref & Age/Sex & $\begin{array}{l}\text { Anticoagulant } \\
\text { therapy }\end{array}$ & INR & $\begin{array}{l}\text { Cre } \\
(\mathrm{mg} / \mathrm{dL})\end{array}$ & $\operatorname{IgA}$ IF & crescents & recovery \\
\hline $\begin{array}{l}\text { Gois et al } \\
\text { [8] }\end{array}$ & $84 / \mathrm{M}$ & acenocoumarol & 2.03 & 4.68 & $3+$ & $(-)$ & Partial \\
\hline Ishii et al [6] & $55 / \mathrm{M}$ & warfarin & 3.75 & 9.01 & $1+$ & $(+)$ & Partial \\
\hline $\begin{array}{l}\text { Moeckel et } \\
\text { al [5] }\end{array}$ & $67 / M$ & dabigatran & 1.6 & 5.5 & $2+/ 3+$ & $(-)$ & Partial \\
\hline $\begin{array}{l}\text { Escoli et al } \\
{[4]}\end{array}$ & $69 / F$ & dabigatran & 2.3 & 8 & $1+$ & $(-)$ & Partial \\
\hline $\mathrm{Ng}$ et al [7] & $56 / F$ & warfarin & 4.95 & 3.6 & $\begin{array}{l}\text { No } \\
\text { data }\end{array}$ & $(-)$ & Partial \\
\hline $\begin{array}{l}\text { Golbin L et } \\
\text { al [10] }\end{array}$ & 76 & fluindione & 2.51 & 3.6 & $1+$ & $(-)$ & Partial \\
\hline $\begin{array}{l}\text { Golbin L et } \\
\text { al [10] }\end{array}$ & 73 & fluindione & 3.8 & 3.5 & $2+$ & $(-)$ & Partial \\
\hline $\begin{array}{l}\text { Golbin L et } \\
\text { al [10] }\end{array}$ & 90 & fluindione & 3.39 & 6.6 & $2+$ & $(-)$ & Died \\
\hline $\begin{array}{l}\text { Golbin L et } \\
\text { al [10] }\end{array}$ & 78 & warfarin & 4.5 & $\mathrm{HD}$ & $3+$ & $(-)$ & Partial \\
\hline $\begin{array}{l}\text { Golbin } L \text { et } \\
\text { al [10] }\end{array}$ & 69 & warfarin & 2.7 & $\mathrm{HD}$ & $2+$ & $(-)$ & $\begin{array}{l}\text { Not } \\
\text { recovery }\end{array}$ \\
\hline $\begin{array}{l}\text { Kalaitzidis } \\
\text { et al [11] }\end{array}$ & 78 & dabigatran & 1.9 & 6.8 & $3+$ & $(-)$ & Total \\
\hline $\begin{array}{l}\text { lkeda et al } \\
\text { [9] }\end{array}$ & $67 / F$ & dabigatran & 2.47 & 3.67 & $1+$ & $(-)$ & Total \\
\hline \multirow{2}{*}{$\begin{array}{l}\text { Brodsky et } \\
\text { al [12] }\end{array}$} & $62 \pm 14$ & \multirow{2}{*}{$\begin{array}{l}\text { Warfarin, } \\
\text { apixaban, heparin, }\end{array}$} & \multirow{2}{*}{$\begin{array}{l}5.6 \pm \\
6\end{array}$} & \multirow{2}{*}{$\begin{array}{l}4.33 \pm \\
1.99\end{array}$} & \multirow{2}{*}{$\begin{array}{l}\text { No } \\
\text { data }\end{array}$} & \multirow[t]{2}{*}{$(-)$} & \multirow[t]{2}{*}{ No data } \\
\hline & $\begin{array}{l}\mathrm{n}=14 / 41 \\
\lg \mathrm{AN}\end{array}$ & & & & & & \\
\hline $\begin{array}{l}\text { Brodsky et } \\
\text { al [2] }\end{array}$ & $38 / F$ & warfarin & 3.9 & 0.9 & $2+$ & $(-)$ & Total \\
\hline $\begin{array}{l}\text { Brodsky et } \\
\text { al [2] }\end{array}$ & $82 / F$ & warfarin & 2.8 & 4.5 & $1+$ & $(-)$ & Total \\
\hline
\end{tabular}

One study showed that only a few patients ( $<1.5 \%)$ with IgA nephropathy presented AKI [13]. Most episodes were triggered by respiratory infections and all the patients had a histomorphological pattern of focal proliferative glomerulonephritis with strong mesangial deposits IgA by IF, and 8-33\% incidence of 
extra capillary crescents, and a 7-16\% incidence of glomerulosclerosis. In addition, several studies have shown a positive correlation between the percentage of glomeruli affected by the crescent formation and the severity of initial and subsequent renal failure. Therefore, we consider that the cause of AKI was anticoagulant-related nephropathy rather than IgA nephropathy because there was no history of prior infection and the presence of numerous RBC tubular casts could not be explained just by these glomerular findings (the mild mesangial proliferation, as well as the deposits of $\lg \mathrm{A}$ by immunofluorescence).

Our patient exhibited more other extraordinary characteristics, including crescent formation. This is the second case to show crescentic form in the glomeruli associated with anti-coagulopathy nephropathy and IgA nephropathy [6]. Golbin $L$ et al also described in 3/13 patients with ARN crescents formations, no one with IgA nephropathy [10]. However, the mechanism of glomerular crescent formation in patients with ARN is not elucidated yet and it is required further investigation.

The steroids may be useful in mitigating the onset of interstitial fibrosis as a consequence of ARN. Specifically, in our patient, our decision to introduce corticosteroid treatment was based mainly on clinical judgment and the extensiveness of pathohistological abnormalities (crescent form), as well as on the intensity of acute tubulointerstitial nephritis. While early steroid administration was reported to accelerate recovery of AKI after gross hematuria in IgA nephropathy [14], the use of prednisolone in ARN is not strongly supported in experimental models and is limited to a single prior case report [15]. Finally, AKI recurrence could happen after the initiation of the same anticoagulant agent or switching to another. [10].

It is remarkable that this is the first case study associated with ARN with a repeat kidney biopsy. As pathogenesis and renal outcome in ARN is not clearly defined, the second renal biopsy informs us that the acute renal tubular injury maybe persists after six months, therefore renal recovery, if it is possible to happen, is considerably delayed.

Consequently, this case demonstrates that ARN is a possible cause of AKI in a patient without previous etiology and recent use of anticoagulant therapy, accompanied by microscopic or gross hematuria. Although treatment options are limited, corticosteroids may potentially suppress the inflammatory response following glomerular hemorrhage and tubular obstruction in the kidney. Considering the poor renal prognosis of ARN, it highlights the necessity for close vigilance of renal function, as well as, urine sediment in patients, who begin on anticoagulation, especially with pre-existing renal diseases, including glomerulopathies and those with glomerular hyperfiltration.

\section{Declarations}

\section{Funding}

None

\section{Conflict of Interests}


There are no conflicts of interest.

\section{Ethics approval}

The patient provided informed consent for publication of the case report.

\section{Consent to participate}

Not applicable

Consent for publication

None

\section{Availability of data and material}

Not applicable

\section{Code availability}

Not applicable

\section{Authors' contributions}

$A C$ wrote the final manuscript whose final version was approved by all the authors; DK, AG actively participated in the treatment of the described patient; HG performed the histopathological analysis; DP supervised the findings of work

\section{References}

1. Wheeler DS, Giugliano RP, Rangaswami J. Anticoagulation-related nephropathy. J Thromb Haemost. 2016 Mar;14(3):461-7

2. Brodsky SV, Satoskar A, Chen J et al. Acute kidney injury during warfarin therapy associated with obstructive tubular red blood cell casts: a report of 9 cases. Am J Kidney Dis 2009 Dec;54(6):1121-6

3. L'Imperio V, Guarnieri A, Pieruzzi F, Sinico RA, Pagni F. Anticoagulant-related nephropathy: a pathological note. J Thromb Thrombolysis 2018 Aug;46(2):260-263

4. Escoli R, Santos P, Andrade S, Carvalho F. Dabigatran-Related Nephropathy in a Patient with Undiagnosed IgA Nephropathy. Case Rep Nephrol 2015;298-261

5. Moeckel GW, Luciano RL, Brewster UC. Warfarin-related nephropathy in a patient with mild IgA nephropathy on dabigatran and aspirin. Clin Kidney J (2013) 6: 507-509

6. Ishii H, Hirai K, Yanai K et al. Warfarin-related nephropathy with acute kidney injury in a patient with immunoglobulin A nephropathy. CEN Case Reports (2018) 7:198-203 
7. $\mathrm{Ng} \mathrm{CY}$, Tan CS, Chin CT et al. Warfarin related nephropathy: a case report and review of the literature. BMC Nephrology (2016) 17:15

8. Góis M, Azevedo A, Carvalho F, Nolasco F. Anticoagulant-related nephropathy in a patient with IgA nephropathy. BMJ Case Rep. 2017; 2017: bcr2016218748.

9. Ikeda M, Tanaka M, Shimoda S et al. Dabigatran-induced anticoagulant-related nephropathy with undiagnosed IgA nephropathy in a patient with normal baseline renal function. CEN Case Reports (2019). 8:292-296

10. Golbin L, Vigneau C, Touchard G et al. Warfarin-related nephropathy induced by three different vitamin K antagonists: analysis of 13 biopsy-proven cases. Clin Kidney J. 2017 Jun; 10(3): 381-388.

11. Kalaitzidis G R, Duni A, Liapis G et al. Anticoagulant-related nephropathy: a case report and review of the literature of an increasingly recognized entity. Int Urol Nephrol 2017 Aug;49(8):1401-1407.

12. Brodsky SV, Satoskar A, Hemminger J et al. Anticoagulant-Related Nephropathy in Kidney Biopsy: A Single-Center Report of 41 Cases. Kidney Med. 2019 1(2):51-56.

13. Kveder R, Lindic J, Ales A, Kovac D, Vizjak A, Ferluga D. Acute Kidney Injury in Immunoglobulin A Nephropathy: Potential Role of Macroscopic Hematuria and Acute Tubulointerstitial Injury. Ther Apher Dial. 2009 Aug;13(4):273-7

14. Moreno JA, Martin-Cleary C, Gutierrez E, et al. AKI associated with macroscopic glomerular hematuria: clinical and pathophysiologic consequences. Clin J Am Soc Nephrol. 2012;7(1):175-84

15. Di Maso V, Carraro M, Bevilacqua E, Bucconi S, Artero ML, Boscutti G. Warfarin-related nephropathy: possible role for the warfarin pharmacogenetic profile. Clin Kidney J. 2014;7(6):605-8.

\section{Figures}



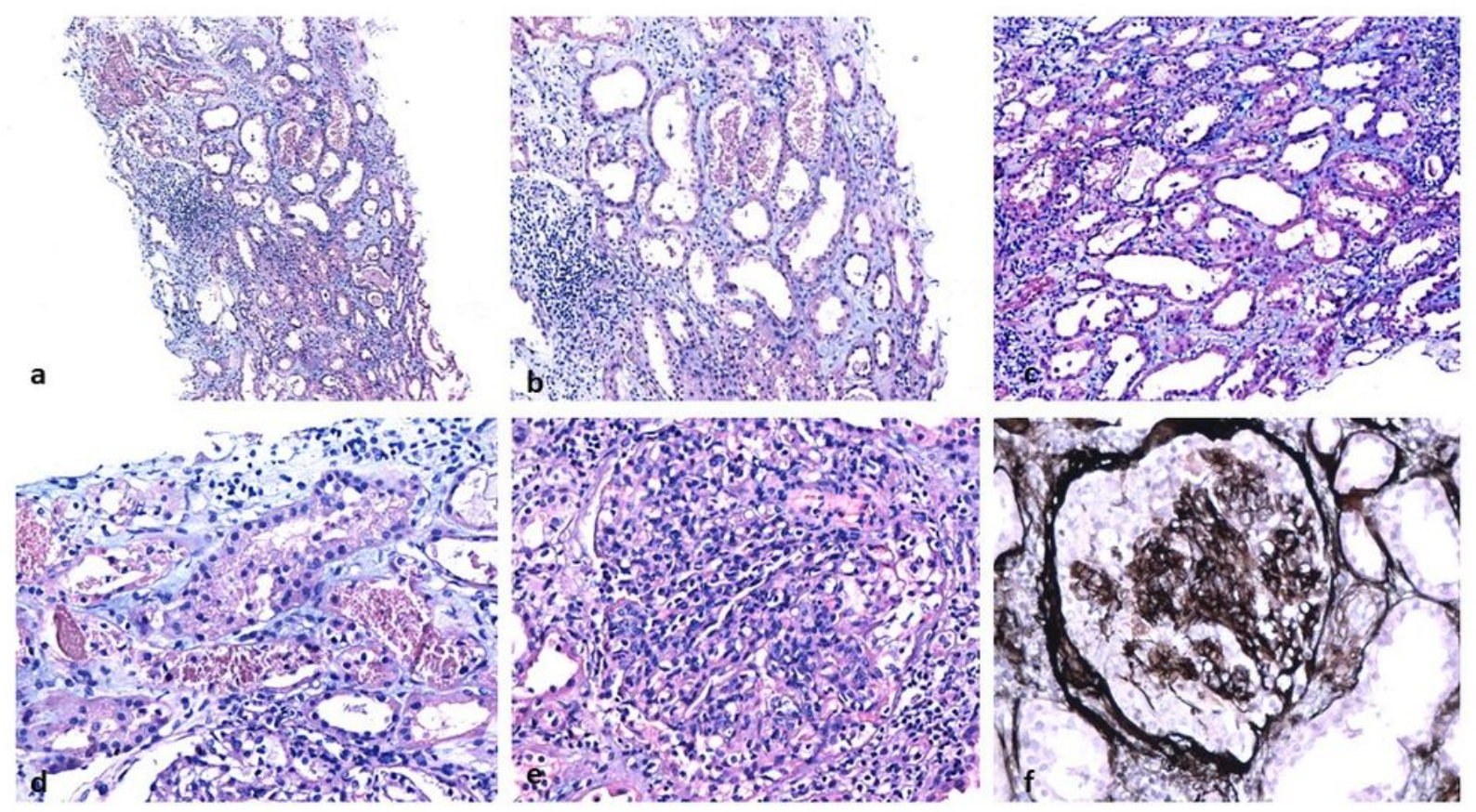

\section{Figure 1}

a,b,c, d Acute tubular injury with red blood cell casts, severe interstitial edema, and inflammation (Hematoxylin and eosin, original magnification $\times 200, x 400$ ). e. A glomerulus with mesangial expansion and cellular crescent formation (Hematoxylin and eosin, original magnification $x 400$ ). f. A glomerulus with mesangial expansion and cellular crescent formation (Masson's trichrome stain, original magnification $\mathrm{x} 400$ ) 

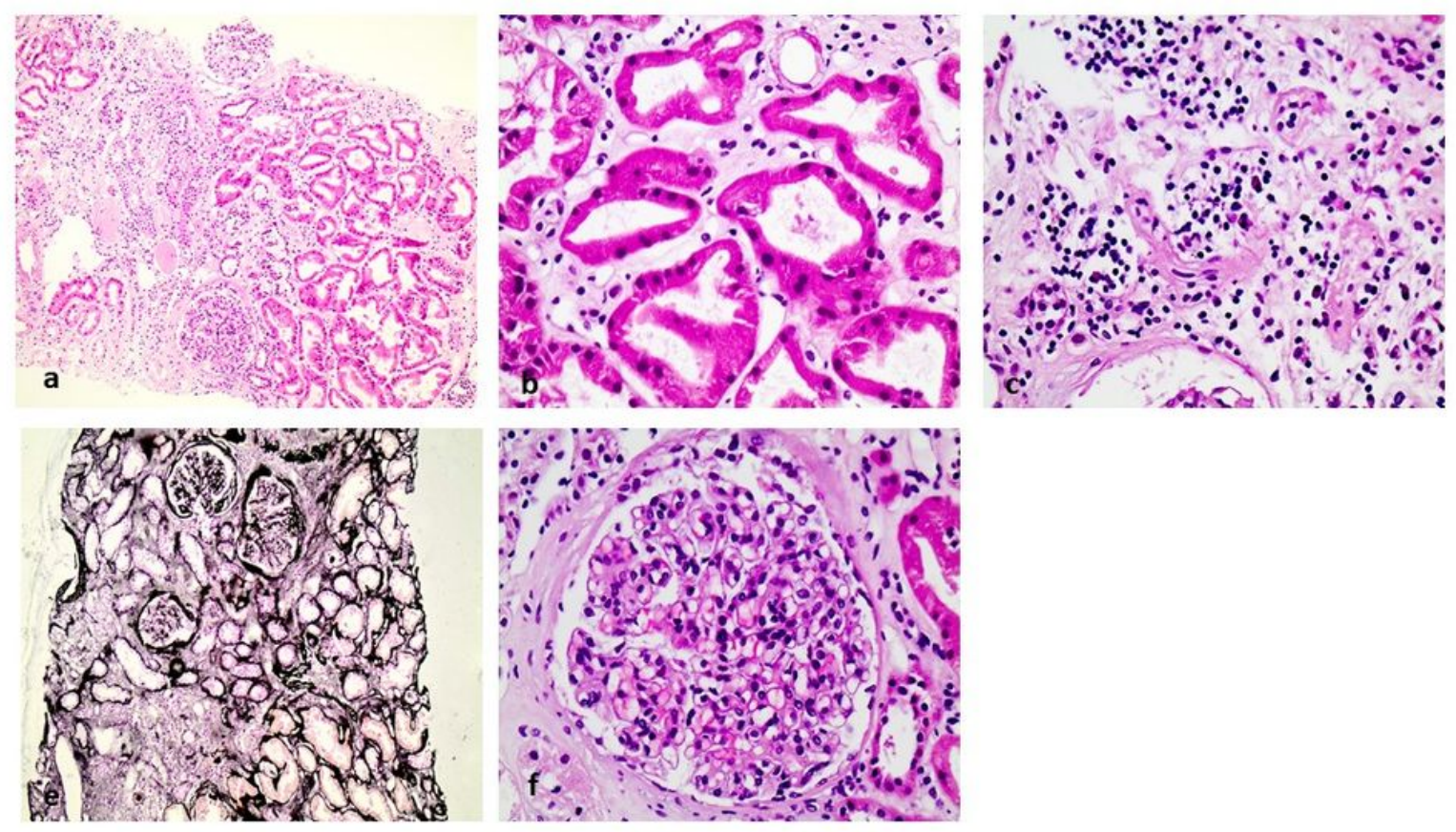

\section{Figure 2}

a,b,c Acute tubular injury without red blood cell casts and interstitial fibrosis. (Hematoxylin and eosin, original magnification x200, x400). d. Acute tubular injury and interstitial fibrosis (Masson's trichrome stain, original magnification $\times 200$ ). f. A glomerulus with mild mesangial expansion (Hematoxylin and eosin, original magnification $\times 400$ )

\section{Supplementary Files}

This is a list of supplementary files associated with this preprint. Click to download.

- CAREchecklistEnglish2013.pdf 